\title{
Microstructural characterization by electron backscatter diffraction of a hot worked $\mathrm{Al}-\mathrm{Cu}-\mathrm{Mg}$ alloy
}

\author{
C.M. Cepeda-Jiménez*, P. Hidalgo, M. Carsí, O.A. Ruano, F. Carreño \\ Department of Physical Metallurgy, CENIM, CSIC, Av. Gregorio del Amo 8, 28040 Madrid, Spain
}

\section{A R T I C L E I N F O}

\section{Article history:}

Received 29 July 2010

Received in revised form

13 December 2010

Accepted 14 December 2010

Available online 22 December 2010

\section{Keywords:}

EBSD

Hardness measurement

Aluminium alloys

Thermomechanical processing

Microstructure

Recrystallization

\begin{abstract}
A B S T R A C T
Hot torsion tests to fracture to simulate thermomechanical processing were carried out on a solutiontreated $\mathrm{Al}-\mathrm{Cu}-\mathrm{Mg}$ alloy ( $\mathrm{Al} 2024-\mathrm{T} 351)$ at constant temperature. Torsion tests were conducted in the range $278-467^{\circ} \mathrm{C}$, and at two strain rates, 2.1 and $4.5 \mathrm{~s}^{-1}$. Electron backscatter diffraction (EBSD) was employed to characterize the microtexture and microstructure before and after testing. The microstructural evolution during torsion deformation at different temperatures and strain rate conditions determines the mechanical properties at room temperature of the Al 2024 alloy since grain refining, dynamic precipitation and precipitate coalescence occur during the torsion test. These mechanical properties were measured by Vickers microhardness tests. At $408^{\circ} \mathrm{C}$ and $2.1 \mathrm{~s}^{-1}$ the optimum combination of solid solution and incipient precipitation gives rise to maximum ductility and large fraction of fine and misoriented grains $\left(f_{\mathrm{HAB}}=54 \%\right)$. In contrast, the increase in test temperature to $467^{\circ} \mathrm{C}$ produces a sharp decrease in ductility, attributed to the high proportion of alloying elements in solid solution. Both the stress-strain flow curves obtained by torsion tests and the final microstructures are a consequence of recovery phenomena and the dynamic nature of the precipitation process taking place during deformation.
\end{abstract}

(c) 2010 Elsevier B.V. All rights reserved.

\section{Introduction}

The 2xxx aluminium alloys, widely used for aeronautical applications, are frequently processed by hot rolling or forging. A good workability is usually obtained in materials that have low flow stress and high ductility [1,2]. However, the intermediate and high forming temperatures result in a number of different microstructural processes that significantly influence the final mechanical response of the alloy [3], such as dynamic-recovery, dynamicrecrystallization and precipitation or dissolution of second phases [4]. These microstructural changes are responsible of the strengthening and softening of the alloys [5].

It is very common to design hot-working processes to improve properties. The hot working and the cooling can be arranged so that the metal is recrystallized to a suitable grain size and texture, usually in preparation for cold forming [6]. Additionally, there are many other cases where retention of the hot-working substructure provides improved mechanical properties, sometimes in conjunction with other strengthening mechanisms. In the 6xxx series alloys, extrusion at solution temperatures and rapid cooling at the die exit are usually followed by an ageing treatment to produce precipitation strengthening [7]. Solution treatment plus processing of the

\footnotetext{
* Corresponding author. Tel.: +34 91 5538900x217; fax: +34 915347425.

E-mail address: cm.cepeda@cenim.csic.es (C.M. Cepeda-Jiménez).
}

2xxx and 7xxx series alloys permits complex ageing for balanced aircraft properties [6].

Torsion tests have been widely used for evaluating the deformation behaviour of materials at elevated temperatures [8-11]. The torsion testing offers the possibility of obtaining large deformations without the occurrence of plastic instability, under conditions simulating those encountered in industrial forming processes, such as hot rolling [1].

In this work, the hot and warm formability of a 2024 aluminium alloy, in the as-solutioned condition, i.e. after heating at $467{ }^{\circ} \mathrm{C}$ to dissolve the hardenable precipitates, has been investigated [12,13]. The tests were conducted at various strain rates and temperatures (cooling from the solution temperature to different test temperatures, and at determined strain rates by means of torsion tests). An extensive microstructural characterization after deformation of the alloy has been carried out using the electron backscatter diffraction technique (EBSD), which is a suitable technique for the analysis of deformed microstructures [14]. EBSD has been used in the present investigation to measure subgrain/grain sizes and to study the texture evolution on a local scale. The objective of this investigation was to evaluate the most favourable conditions for hot workability, similar to those employed in industrial rolling process, and to study the microstructure evolution after deformation by torsion. The effect of processing on the microstructure is discussed in terms of solid solution hardening and dynamic phenomena, such as recovery and precipitation. 


\section{Experimental procedure}

\subsection{Materials}

The aluminium alloy used in the present study was a rolled $\mathrm{Al}$ 2024-T351 plate of $12 \mathrm{~mm}$ in thickness. The composition in atomic percentage of the alloy is included in Table 1 and some mechanical properties are summarized in Table 2.

\subsection{Torsion tests}

Hot torsion tests were carried out on a computer-controlled and hydraulically powered torsion machine with the ends of the sample axially fixed. The hot torsion machine, SETARAM 7MN, has been described elsewhere [8]. The torsion samples were machined so that the gauge length coincided with the plate rolling direction. Samples $17 \mathrm{~mm}$ long and $3 \mathrm{~mm}$ radius in the gauge zone were torsioned to fracture at constant temperature and strain rate. In this study, hot torsion temperatures were selected between 278 and $467^{\circ} \mathrm{C}$, and two strain-rates $(\dot{\varepsilon})$ of 2.1 and $4.5 \mathrm{~s}^{-1}$ were considered. These strain rates are comparable to those used in an industrial process. Then, Al 2024 samples were solutioned at $467^{\circ} \mathrm{C}$ for $10 \mathrm{~min}$ and hold for $15 \mathrm{~min}$ for microstructural stabilization, and after, they were cooled in $2 \mathrm{~min}$ to testing temperature and tested. The range of deformation parameters of the torsion test ( $T$ and $\dot{\varepsilon}$ ) covered the conditions used during hot rolling of multilayer materials containing this aluminium alloy, which were processed previously $[15,16]$. The rolling conditions, that correspond also to those required in the industry for a real hot-rolling process, start at a high temperature of about $470^{\circ} \mathrm{C}$, decreasing during the passes down to about $270^{\circ} \mathrm{C}$.

The samples were introduced in a silica tube with an argon inlet, to ensure protection against oxidation, and heated by a high frequency induction furnace. The temperature during the torsion test was measured by a two-colour pyrometer. Immediately after fracture, the samples were water quenched in less than $0.5 \mathrm{~s}$ in order to retain the deformation microstructure, specially the grain size.

The torsion tests provided directly the curves of torque, $\Gamma$, versus number of turns, $N$. The effective stress $(\sigma)$, the effective strain $(\varepsilon)$ and the strain rate $(\dot{\varepsilon})$ were calculated by means of the following relationships $[17,18]$ :

$\sigma=\frac{\Gamma \sqrt{3}}{2 \pi R^{3}}\left(3+m+\theta^{\prime}\right) \quad \varepsilon=\frac{2 \pi R N}{L \sqrt{3}} \quad \dot{\varepsilon}=\frac{2 \pi R \dot{N}}{L \sqrt{3}}$

where $R$ is the sample radius, $L$ is the gauge length, $m$ is the strain rate sensitivity and $\theta^{\prime}$ is the work hardening exponent:

$m=\left.\frac{\partial \ln \Gamma}{\partial \ln \dot{\varepsilon}}\right|_{\varepsilon, \mathrm{T}} \quad \theta^{\prime}=\left.\frac{\partial \ln \Gamma}{\partial \ln \varepsilon}\right|_{\dot{\varepsilon}, \mathrm{T}}$

\subsection{Microstructures}

Electron backscatter diffraction (EBSD) was employed in the present investigation to characterize the microtexture and microstructure of the $\mathrm{Al} 2024$ alloy tested by hot torsion.

The samples for EBSD observation were prepared on sections parallel to the torsion axis at a distance of $0.7 R$, with $R$ being the radius of the gauge length as illustrated in Fig. 1. The EBSD scans were carried out at the centre of the observation surface. The initial grain size of the alloy for each torsion condition was determined in the non-deformed region (head) of the torsion samples.

Orientation maps were performed by EBSD in a scanning electron microscope (SEM) JEOLJSM 6500F, with a fully automatic EBSD attachment, HKL Technology, operating at an accelerating voltage and a working distance of $20 \mathrm{kV}$ and $15 \mathrm{~mm}$, respectively. The corresponding data processing was carried out using HKL Channel 5 software. The area mapping for the torsion tested samples was

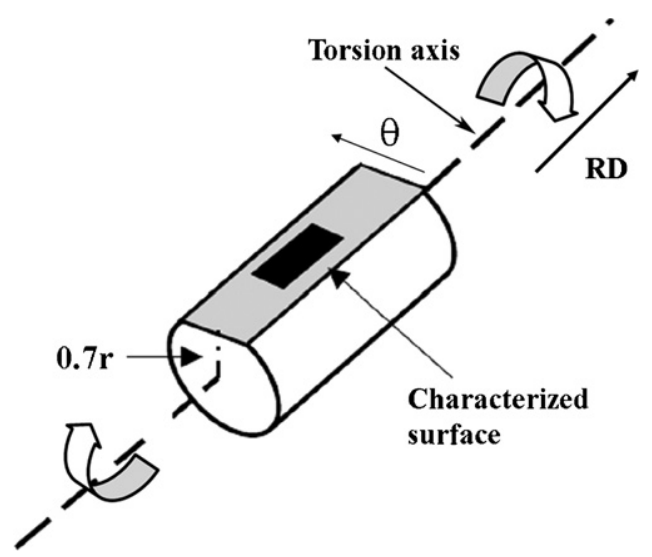

Fig. 1. Illustration of the flat at a distance of $0.7 R$ of the torsion sample that was used for EBSD analysis.

$430 \mu \mathrm{m} \times 343 \mu \mathrm{m}$ with a step size of $0.25 \mu \mathrm{m}$. The low angle grain boundary (LAB) was defined by a misorientation between adjacent grains of $2^{\circ}<\theta<15^{\circ}$, and the high angle grain boundary (HAB) was defined by $\theta>15^{\circ}$. The HAB and LAB are shown as black and white lines respectively on the maps. Specimens were mechanically polished and then electropolished in a 30\% nitric acid solution in methanol at $-28^{\circ} \mathrm{C}$ and $15 \mathrm{~V}$.

\subsection{Microhardness test}

Vickers microhardness measurements for torsioned Al 2024 alloy were carried out as a function of the distance from the middle of the sample of the transversal section, in order to observe the hardness gradient across the sample. Loads of $100 \mathrm{~g}$ during $15 \mathrm{~s}$ were considered. The distance to the centre of the sample was measured from the indentation centre using image analysis software.

\section{Results}

\subsection{Torsion tests}

Fig. 2a shows the results of the torsion tests to fracture carried out at temperatures ranged between 278 and $467^{\circ} \mathrm{C}$ and at a strain rate of $2.1 \mathrm{~s}^{-1}$. Fig. 2b shows stress-strain curves obtained under the same experimental conditions of temperature as Fig. 2a but at a strain rate of $4.5 \mathrm{~s}^{-1}$. Every curve shows a rapid increase in the stress to a peak value $\left(\sigma_{\mathrm{p}}\right)$, followed by a gradual softening until the rupture of the sample. The strain corresponding to the peak stress increases slightly with the decrease in deformation temperature. A steady state flow stress is observed at high $T$ and low $\dot{\varepsilon}$, especially for the sample tested at $408^{\circ} \mathrm{C}$ and $2.1 \mathrm{~s}^{-1}$. Adiabatic heating correction was not conducted because the changes expected should be small due to the high thermal conductivity of aluminium.

In general, the peak stresses increase slightly with increasing strain rate and decrease with increasing test temperature. On the other hand, the ductility shows the opposite behaviour to the peak stress; i.e. the fracture strain of the tested samples decreases with increasing strain rate, and increases with increasing test temperature for both strain rates considered up to about $408^{\circ} \mathrm{C}$, where a maximum in ductility is observed at both strain rates. Also, it is worth noting the decrease in ductility at the highest test temperature of $467{ }^{\circ} \mathrm{C}$ and both strain rates. Additionally, Fig. 2 shows a strong dependence of the equivalent strain to fracture $\left(\varepsilon_{\mathrm{F}}\right)$ with the strain rate, especially at higher temperatures. Finally, the flow softening observed in the stress-strain curves for both strain rates is sharper at lower test temperatures (warm forming conditions). 
Table 1

Chemical composition of the as-received Al 2024-T351 alloy (at.\%) (T351: solution heat treatment plus stress relieving by stretching and finally natural ageing).

\begin{tabular}{|c|c|c|c|c|c|c|c|c|c|}
\hline Alloy & $\mathrm{Si}$ & $\mathrm{Fe}$ & $\mathrm{Cu}$ & $\mathrm{Mn}$ & $\mathrm{Mg}$ & $\mathrm{Cr}$ & $\mathrm{Zn}$ & $\mathrm{Ti}$ & $\mathrm{Ni}$ \\
\hline 2024-Т351 & 0.07 & 0.04 & 2.46 & 0.21 & 1.26 & 0.04 & 0.14 & 0.02 & 0.06 \\
\hline
\end{tabular}

Table 2

Mechanical properties of the as-received Al 2024-T351 alloy (UTS: ultimate tensile strength; YS: yield stress; HV: Vickers Hardness).

\begin{tabular}{|c|c|c|c|c|}
\hline Alloy & $\mathrm{UTS}^{\mathrm{a}}(\mathrm{MPa})$ & $\mathrm{YS}^{\mathrm{a}}(\mathrm{MPa})$ & $\mathrm{HV}$ & Elongation $^{\mathrm{a}}(\%)$ \\
\hline 2024-Т351 & 435 & 285 & 138 & 12 \\
\hline
\end{tabular}

a Data provided by the alloy maker from tensile tests.

\subsection{Microstructure}

Fig. 3 shows EBSD maps of the as-received Al 2024-T351 alloy in the LT orientation (longitudinal-transversal) (Fig. 3a), and the microstructures corresponding to the undeformed part (head) of a torsion sample soaked at $467^{\circ} \mathrm{C}$ for $15 \mathrm{~min}$ and torsion tested at $467^{\circ} \mathrm{C}$ plus water quenched (Fig. 3b), or soaked at $467^{\circ} \mathrm{C}$ and torsion tested at $278^{\circ} \mathrm{C}$ (Fig. 3c).

The EBSD maps have been colour coded according to the inverse pole figure (IPF) shown in the inset, and the colours represent the crystallographic orientations parallel to the normal direction (ND) for the rolled as-received Al 2024 alloy (Fig. 3a), and orientations parallel to the shear plane normal (Fig. $3 \mathrm{~b}$ and $\mathrm{c}$ ) for the torsion tested samples. The colours will appear as a gray scale in a printed version of this paper.

The microstructure of the as-received Al 2024-T351 alloy (Fig. 3a) consists of recrystallized grains, with spacing between high-angle grain boundaries (HABs) in the normal rolling direction of about $7.4 \mu \mathrm{m}$. The fraction of high-angle grain boundaries $\left(f_{\mathrm{HAB}}\right)$ was $92 \%$. In addition, large insoluble iron-rich intermetallic
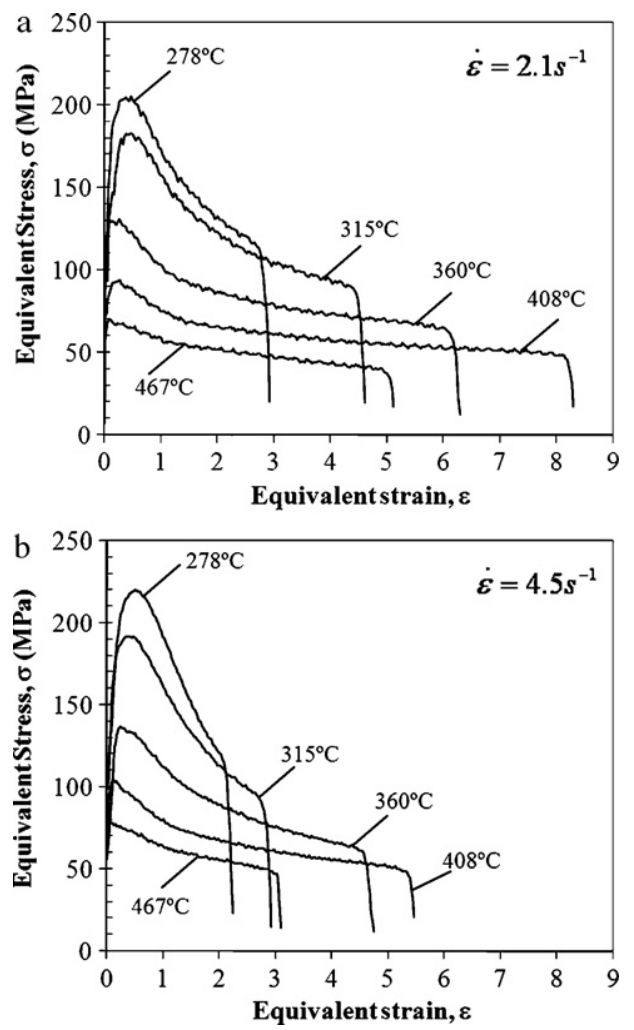

Fig. 2. Stress versus strain curves for the Al 2024-T351 alloy deformed in torsion. The deformation temperatures were in the range $278-467{ }^{\circ} \mathrm{C}$ and the strain rates were (a) $\dot{\varepsilon}=2.1 \mathrm{~s}^{-1}$ and (b) $\dot{\varepsilon}=4.5 \mathrm{~s}^{-1}$. particles and partially soluble constituent particles were observed to be randomly distributed, and they are ranged in size from 0.5 to $5 \mu \mathrm{m}$. These particles are formed during alloy solidification and they are non-indexed in the EBSD maps. Previous works $[19,20]$ have reported in this alloy three types of large intermetallic particles, $\mathrm{Al}_{7} \mathrm{Cu}_{2} \mathrm{Fe},(\mathrm{Al}, \mathrm{Cu})_{6} \mathrm{Fe}$ and $\mathrm{Mg}_{2} \mathrm{Si}$.

Fig. $3 \mathrm{~b}$ and $\mathrm{c}$ shows the EBSD maps of the undeformed head of torsion samples tested under different conditions. Both EBSD maps show a very large recrystallized grain size elongated in the original rolling direction $(\sim 40 \mu \mathrm{m}$ in thickness). A treatment of this alloy at high temperature such as $467^{\circ} \mathrm{C}$ is known to give abnormal grain growth within times of less than $1 \mathrm{~h} \mathrm{[21].} \mathrm{This} \mathrm{abnormal}$ grain growth is produced during static annealing at $467{ }^{\circ} \mathrm{C}$, and the grain size does not change during the subsequent cooling to the test temperatures (Fig. 3c).

Fig. 4 shows EBSD maps of tested samples at different hot torsion conditions. The shear direction is vertical and the radial direction is normal to the page. In addition, the fraction of high-angle grain boundaries $\left(f_{\mathrm{HAB}}\right)$ and the mean correlated misorientation calculated from the EBSD maps (Fig. 4), as a function of hot torsion conditions, are given in Table 3. A correlated misorientation value displays the misorientation between neighbouring points in an EBSD map [22].

In general, the EBSD maps at all torsion test conditions of Fig. 4 have a common microstructure constituted by the original grains elongated around the torsion axis in a spiral, and containing a substructure whose cell size varies as a function of test conditions. The angle between the long grain axis and the torsion axis corresponds to that expected from the deformation geometry [23].

The microstructure corresponding to the Al 2024 tested at $467^{\circ} \mathrm{C}$ and $2.1 \mathrm{~s}^{-1}$ (Fig. 4a) consists of chains of equiaxed or slightly elongated subgrains developed inside the original elongated grains. Thus, the original grains are subdivided by the formation of these low-angle boundaries. The average subgrain size developed at the given torsion conditions is $3.4 \mu \mathrm{m}$, and $f_{\mathrm{HABs}}$ and $\bar{\theta}_{c}$ is $36 \%$ and $16^{\circ}$, respectively. With the decrease of test temperature to $408^{\circ} \mathrm{C}$ and $2.1 \mathrm{~s}^{-1}$ (Fig. 4b), the original HABs and the new deformationinduced low-angle boundaries rotate towards the shear direction, as a consequence of higher $\varepsilon_{\mathrm{F}}$ (Fig. 2). Furthermore, new fine equiaxed grains surrounded by high-angle grain boundaries are developed inside the initial grains. In addition, the subgrain size

Table 3

Fraction of high-angle boundaries $f_{\mathrm{HAB}}(\%)$ and mean correlated misorientation calculated from EBSD maps illustrated in Fig. 4.

\begin{tabular}{lllllr}
\hline$T\left({ }^{\circ} \mathrm{C}\right)$ & $\dot{\varepsilon}=2.1 \mathrm{~s}^{-1}$ & & & $\dot{\varepsilon}=4.5 \mathrm{~s}^{-1}$ & \\
\cline { 2 - 3 } \cline { 5 - 6 } & $f_{\mathrm{HAB}}(\%)$ & $\bar{\theta}_{c}$ & & $f_{\mathrm{HAB}}(\%)$ & $\bar{\theta}_{c}$ \\
\hline 467 & 36 & 16 & 44 & 19 \\
408 & 54 & 23 & 19 & 10 \\
360 & 47 & 20 & 41 & 7 \\
315 & 22 & 10 & 24 & 7 \\
278 & 25 & 15 & 9 & 7 \\
\hline
\end{tabular}



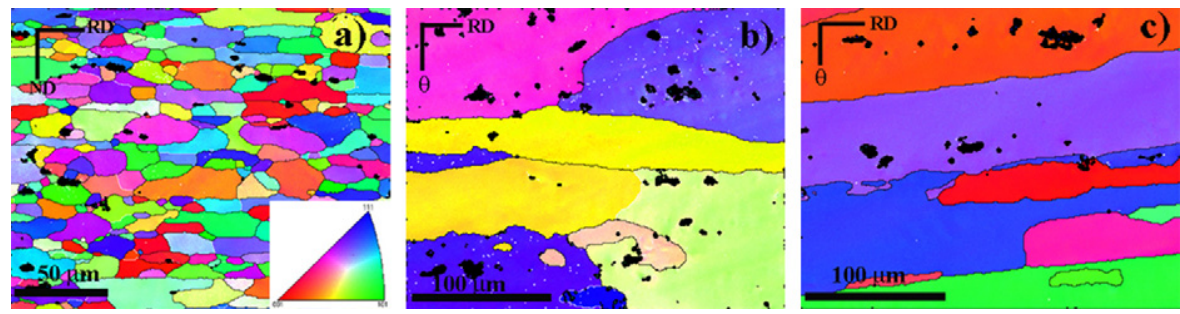

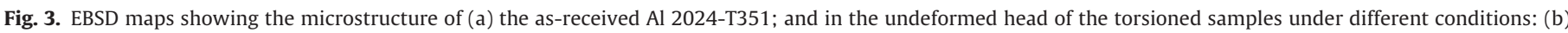
$467{ }^{\circ} \mathrm{C}, \dot{\varepsilon}=4.5 \mathrm{~s}^{-1}$; and (c) $278^{\circ} \mathrm{C}, \dot{\varepsilon}=2.1 \mathrm{~s}^{-1}$.

continued to decrease, as a consequence of the higher stress during the torsion test with respect to $467^{\circ} \mathrm{C}$. The average (sub)grain size at this conditions is $1.9 \mu \mathrm{m}$, and the $f_{\mathrm{HAB}}$ and $\bar{\theta}_{c}$ are considerably increased to $54 \%$ and $23^{\circ}$, respectively. Thus, the final microstructure at $408^{\circ} \mathrm{C}$ and $2.1 \mathrm{~s}^{-1}$ consists of a very dense HABs network. The high strain experimented at this test condition $\left(\varepsilon_{\mathrm{F}} \sim 8.2\right)$ leads to the gradual build-up of higher misorientation between the neighbouring subgrains.

As shown in Fig. 4d and e, the microstructures at a higher strain rate $\left(4.5 \mathrm{~s}^{-1}\right)$ than those illustrated in Fig. $4 \mathrm{a}$ and $\mathrm{b}\left(2.1 \mathrm{~s}^{-1}\right)$, at the same high test temperatures, are less homogeneous and less developed as indicated by the large variations in LABs and HABs populations. In fact, at $408^{\circ} \mathrm{C}$ and $4.5 \mathrm{~s}^{-1}$ (Fig. 4e) the microstructure is poorly misoriented with a $f_{\mathrm{HAB}}=19 \%$ and $\bar{\theta}_{c}=10^{\circ}$. Such difference is attributed to higher ductility for the Al 2024 tested at low strain rate and at such temperature, i.e. $\varepsilon=8.2$ and 5.5 at 2.1 and at $4.5 \mathrm{~s}^{-1}$, respectively.

At $360^{\circ} \mathrm{C}$ and $2.1 \mathrm{~s}^{-1}$ (Fig. 4c) grain and subgrain structures are observed to be rather heterogeneous and vary substantially from area to area, although the subgrain size continues refining respect
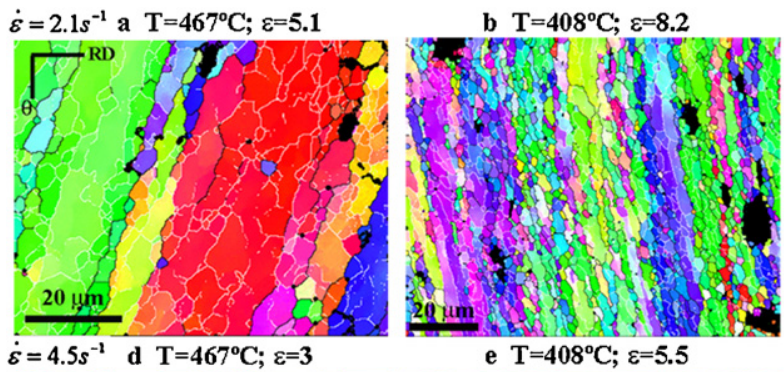

e $\mathrm{T}=408^{\circ} \mathrm{C} ; \varepsilon=5.5$

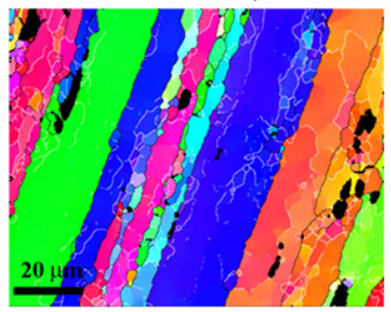

$\dot{\varepsilon}=2.1 \mathrm{~s}^{-1} \mathrm{~g} \mathrm{~T}=315^{\circ} \mathrm{C} ; \varepsilon=4.6$

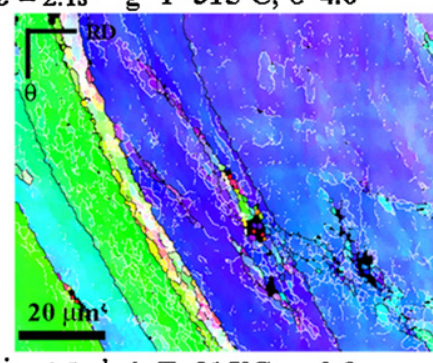

$\dot{\varepsilon}=4.5 \mathrm{~s}^{-1}$ i $\mathrm{T}=315^{\circ} \mathrm{C} ; \varepsilon=2.9$
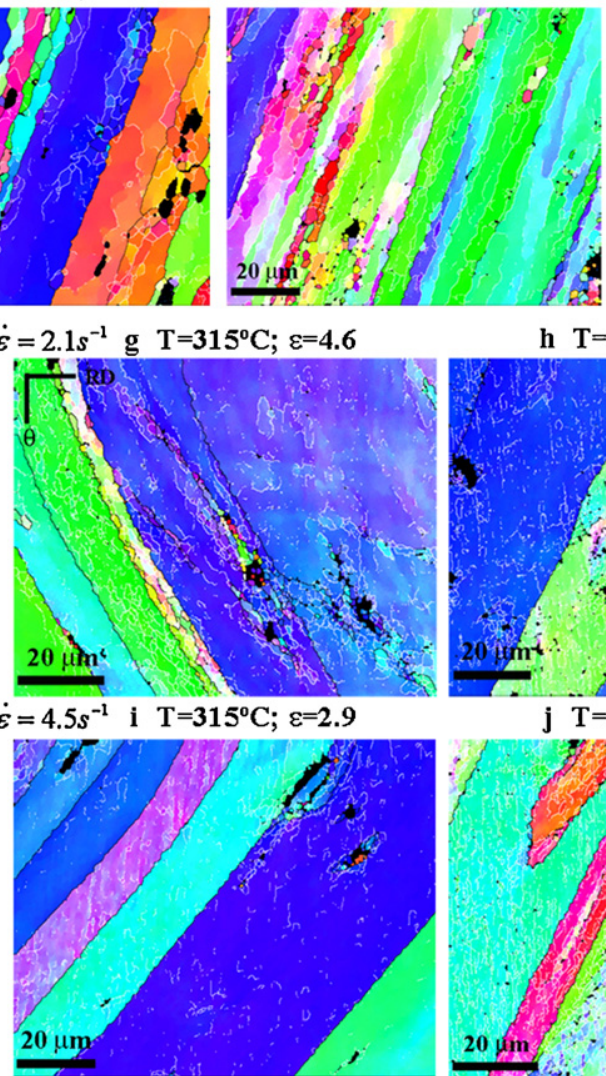

c $\mathrm{T}=360^{\circ} \mathrm{C} ; \varepsilon=6.2$

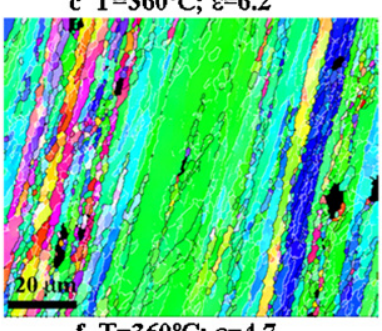

f $\mathrm{T}=360^{\circ} \mathrm{C} ; \varepsilon=4.7$

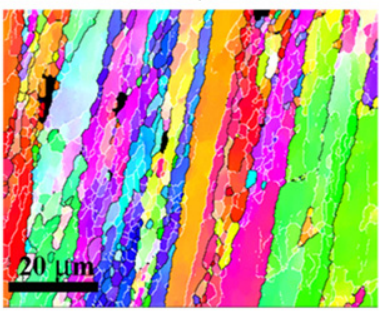

h $\mathrm{T}=278^{\circ} \mathrm{C} ; \varepsilon=\mathbf{2 . 9}$

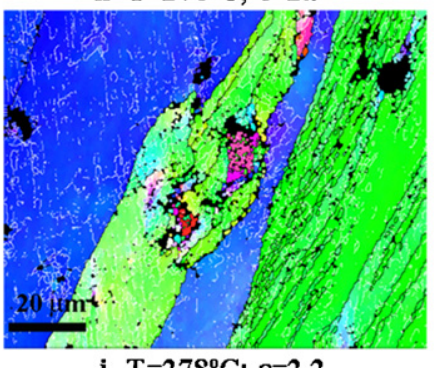

j $\mathrm{T}=278^{\circ} \mathrm{C} ; \varepsilon=2.2$

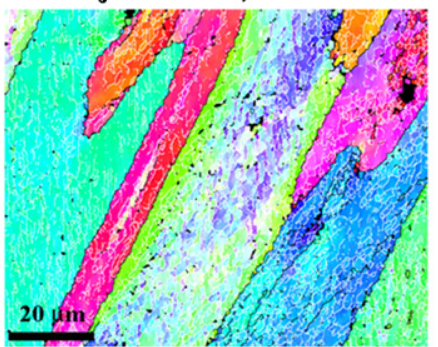

Fig. 4. EBSD maps showing the microstructure of quenched Al 2024 samples deformed at different torsion conditions: (a) $467^{\circ} \mathrm{C}, \dot{\varepsilon}=2.1 \mathrm{~s}^{-1}$; (b) $408^{\circ} \mathrm{C}, \dot{\varepsilon}=2.1 \mathrm{~s}^{-1}$; (c) $360^{\circ} \mathrm{C}$, $\dot{\varepsilon}=2.1 \mathrm{~s}^{-1}$; (d) $467^{\circ} \mathrm{C}, \dot{\varepsilon}=4.5 \mathrm{~s}^{-1}$; (e) $408^{\circ} \mathrm{C}, \dot{\varepsilon}=4.5 \mathrm{~s}^{-1}$; (f) $360^{\circ} \mathrm{C}, \dot{\varepsilon}=4.5 \mathrm{~s}^{-1}$; (g) $315^{\circ} \mathrm{C}, \dot{\varepsilon}=2.1 \mathrm{~s}^{-1}$; (h) $278^{\circ} \mathrm{C}, \dot{\varepsilon}=2.1 \mathrm{~s}^{-1}$; (i) $315^{\circ} \mathrm{C}, \dot{\varepsilon}=4.5 \mathrm{~s}^{-1} ;$ (j) $278^{\circ} \mathrm{C}, \dot{\varepsilon}=4.5 \mathrm{~s}^{-1}$. 

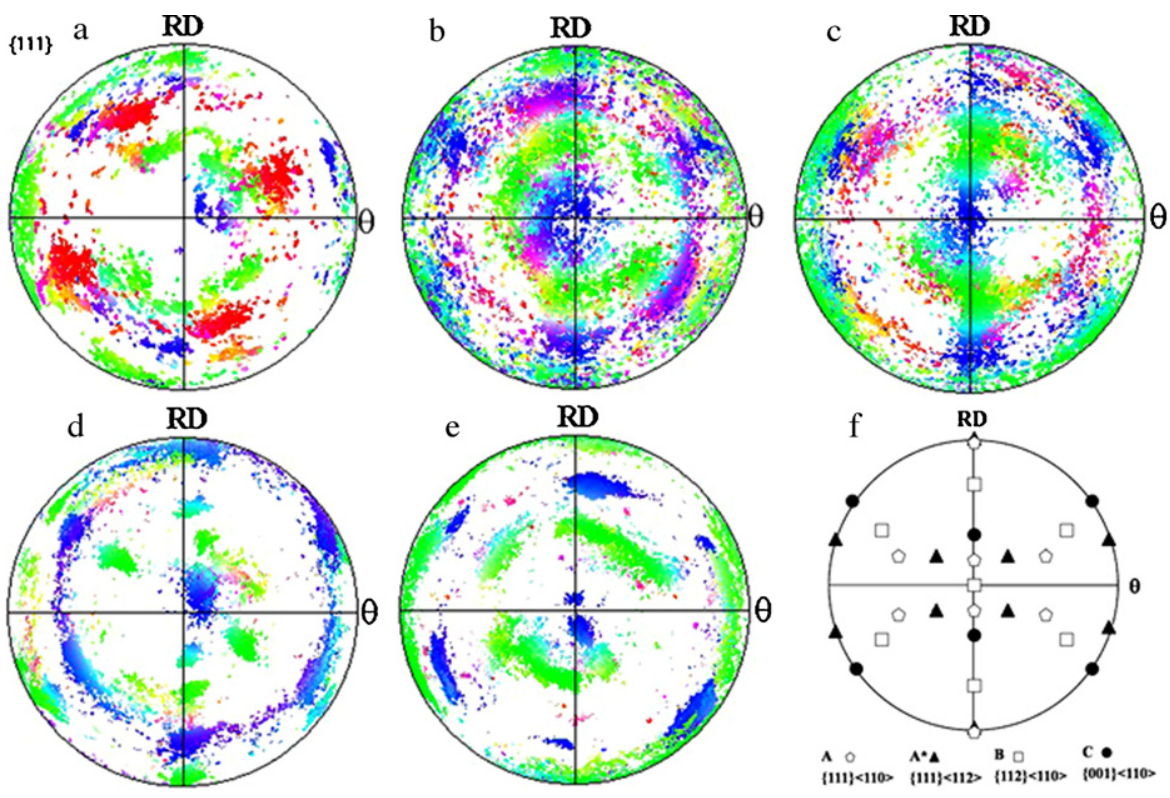

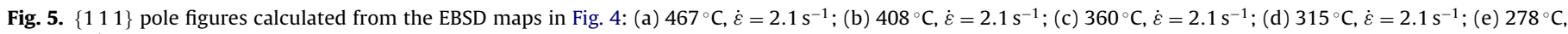
$\dot{\varepsilon}=2.1 \mathrm{~s}^{-1}$; (f) main torsion components on the $\{111\}$ pole figure.

to higher test temperature, being equal to $1.3 \mu \mathrm{m}$. In addition the $f_{\mathrm{HAB}}$ is decreased to $47 \%$, regarding to the sample tested at $408^{\circ} \mathrm{C}$ and the same strain rate. After deformation at $360^{\circ} \mathrm{C}$ and higher strain rate of $4.5 \mathrm{~s}^{-1}$ (Fig. 4f), elongated grains filled with subboundaries alternated with almost sub-boundaries-free grains are observed. At this test condition subgrain sizes are larger $(1.5 \mu \mathrm{m})$, and $f_{\mathrm{HAB}}=41 \%$ is lower than that for samples tested at higher temperatures and lower $\dot{\varepsilon}$ (Fig. $4 \mathrm{~b}$ and c).

Finally, torsion samples tested at 315 and $278^{\circ} \mathrm{C}$ and for both strain rates (Fig. $4 \mathrm{~g}-\mathrm{j}$ ) exhibit coarse grains, with an apparent work hardened microstructure with poorly developed substructure. Furthermore, the $f_{\mathrm{HAB}}$ for these torsion test conditions are drastically reduced (Table 3 ), specially for samples tested at the lowest temperature and the highest strain rate, i.e. for $\mathrm{Al} 2024$ torsion tested at $278^{\circ} \mathrm{C}$ and $4.5 \mathrm{~s}^{-1}$ with $f_{\mathrm{HAB}}=9 \%$ and $\bar{\theta}_{c}=7^{\circ}$. This low mean misorientation is due to the high level of low angle boundaries and dislocation structures within the grains.

In general, it was found that the magnitude of the misorientation between adjacent subgrains $\left(\bar{\theta}_{c}\right)$ was reduced with decreasing test temperature, due to an increase in low angle boundaries, following the same trend that $f_{\mathrm{HAB}}$.

The texture data for torsion samples are represented using the sample orientations given in Fig. 1. When Miller indexes are used to present orientations, $\{h k l\}$ is parallel to the $z$ direction (torsion axis) and $\langle u v w\rangle$ is parallel to the shear direction $(\theta)$, that is, the representation is in the form $\{z\}<\theta>$ [24]. The textures for the Al 2024 tested by torsion at different temperatures and $2.1 \mathrm{~s}^{-1}$ are given as $\left\{\begin{array}{lll}1 & 1 & 1\end{array}\right\}$ pole figures in Fig. 5 . These are typical FCC shear textures and are schematically displayed in Fig. 5f. FCC metals like aluminium, with high stacking fault energy, present stable torsion textures consisting of a strong $\{h k l\}<110>B$ fibre and a less strong $\{111\}\langle u v w>$ A fibre [25], i.e. there is a strong tendency for the slip direction to become aligned with the shear direction. In aluminium, the ideal $\left\{\begin{array}{lll}1 & 0 & 0\end{array}\right\}<110>$ (Corientation) and $\left\{\begin{array}{lll}1 & 1 & 2\end{array}\right\}<110>$ (B orientation) components are normally positions of high orientation density on the B fibre [26].

The texture corresponding to the sample torsion tested at $467{ }^{\circ} \mathrm{C}$ (Fig. 5a) shows a weak texture with an incipient development of the commonly observed shear texture components, i.e. A

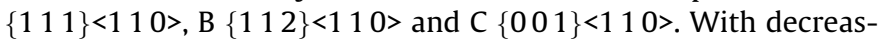

ing test temperature the texture intensity strengthens and the main shear texture components become more defined. At 408 (Fig. 5b) and $360^{\circ} \mathrm{C}$ (Fig. 5c) the main texture component is $\mathrm{C}$ orientation $(\{001\}<110>$ ), while at lower temperatures of 315 (Fig. $5 d)$ and $278^{\circ} \mathrm{C}$ (Fig. 5e), B orientation $\left(\left\{\begin{array}{ll}1 & 1\end{array}\right\}<110>\right.$ ) is the dominant texture component.

\subsection{Microhardness test}

The microhardness of torsioned samples, followed by waterquenching and finally, natural ageing of the residuary elements in solid solution for 4 months is plotted in Fig. 6. Fig. 6a shows the microhardness for torsioned $\mathrm{Al} 2024$ alloy as a function of the distance from the middle of the sample of the transversal section. Results from various samples at different torsion temperatures, and a strain rate of $2.1 \mathrm{~s}^{-1}$ are given. In addition, Fig. $6 \mathrm{~b}$ plots the results obtained for $\dot{\varepsilon}=4.5 \mathrm{~s}^{-1}$. The horizontal dotted lines in Fig. $6 \mathrm{a}$ and $\mathrm{b}$ indicate the microhardness value corresponding to the as-received Al 2024-T351 alloy (138HV). For all torsion conditions, microhardness gradients across the diameter were not observed.

It is well known that precipitation hardening is one of the most effective strengthening mechanisms to improve the strength in aluminium alloys [27]. All torsioned samples showed lower microhardness values than that of the as-received $\mathrm{Al} 2024$ alloy, 138HV. It is observed that the microhardness decreases with decreasing test temperature, varying from an average value of $132 \mathrm{HV}$ at $467{ }^{\circ} \mathrm{C}$ and $4.5 \mathrm{~s}^{-1}$, to $97 \mathrm{HV}$ at $278^{\circ} \mathrm{C}$ and $2.1 \mathrm{~s}^{-1}$. This unexpected behaviour will be explained in the discussion in terms of solid solution available for precipitation hardening.

\section{Discussion}

In this work, the aeronautical $\mathrm{Al} 2024$ alloy was deformed by hot torsion after solution treatment, in a range of temperatures $\left(278-467^{\circ} \mathrm{C}\right)$ and two strain rates $\left(2.1\right.$ and $\left.4.5 \mathrm{~s}^{-1}\right)$, and the obtained microstructures were characterized by EBSD and microhardness tests.

In general, the stress-strain curves (Fig. 2) show a typical behaviour for metals tested in torsion at high temperature, i.e. the peak stresses increase with decreasing test temperature, and the 

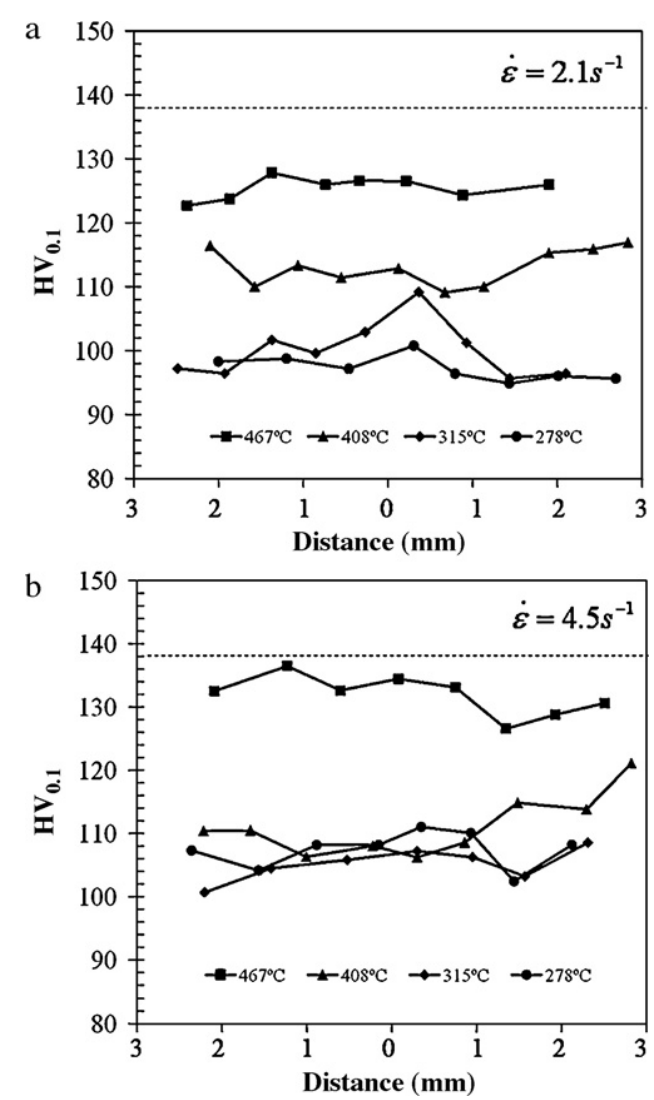

Fig. 6. Vickers microhardness (100g, 15s) of the Al 2024 alloy tested by torsion at different temperatures and two different strain rates, as a function of the distance through the gauge diameter. (a) $\dot{\varepsilon}=2.1 \mathrm{~s}^{-1}$ and (b) $\dot{\varepsilon}=4.5 \mathrm{~s}^{-1}$.

ductility increases with increasing test temperature. This trend is observed until a test temperature of $408^{\circ} \mathrm{C}$. At the highest test temperature, $467{ }^{\circ} \mathrm{C}$, this general trend is not followed and the ductility decreases. Additionally, the presence of a plateau in the stress-strain curves that can be taken as steady state starts to be observed at about $360^{\circ} \mathrm{C}$. This steady state is considered as a balance of hardening and softening processes. The hardening arises from obstacles to dislocation motion, such as elements in solid solution and incipient fine precipitates induced by static cooling to test temperature and also by the torsion deformation. In contrast, the softening can be associated to DRV.

The Al 2024 alloy has been extensively studied in the last decades. Differential scanning calorimetry (DSC) has been frequently used in order to investigate the ageing sequence, and the precipitation temperatures and kinetics of this type of aluminium alloys $[3,12,28]$. According to the composition and the $\mathrm{Cu}: \mathrm{Mg}$ ratio of the Al 2024 alloy studied in the present study, two different stable phases can be present in an overaged sample: $\theta\left(\mathrm{CuAl}_{2}\right)$ and $\mathrm{S}$ $\left(\mathrm{CuMgAl}_{2}\right)$ [29]. Precipitation phenomena occur during DSC below $430^{\circ} \mathrm{C}$. Additionally, it was observed by X-ray diffraction that the $\mathrm{CuAl}_{2}$ diffraction lines disappear at $320^{\circ} \mathrm{C}$ (on heating) [30]. Thus, although no solid solution quantification has been done, we can assume that the following microstructural changes occur during the homogenization treatment and during the hot-torsion tests: (i) a prolonged homogenization for $30 \mathrm{~min}$ at $467^{\circ} \mathrm{C}$ as performed in this study, largely removes $\theta$ and $S$ precipitates, bringing copper and magnesium atoms into solid solution [12]; (ii) the subsequent cooling to torsion test temperatures together with deformation produces that very fine particles start to precipitate dynamically at high torsion temperatures $\left(408\right.$ and $\left.360^{\circ} \mathrm{C}\right)$ from solid solution; (iii) at lower temperatures ( 315 and $278^{\circ} \mathrm{C}$ ), a considerable amount of precipitation must occur as a result of slow cooling and deformation (dynamic precipitation). Thus, the applied deformation helps to precipitate any supersaturated solid solution present at testing temperature, and a monotonic increment of precipitates with diminishing testing temperature is expected.

Accordingly, the microstructure obtained from the EBSD maps for the test conditions of $408^{\circ} \mathrm{C}$ and $2.1 \mathrm{~s}^{-1}$ (Fig. 4b) shows a homogeneous small (sub)grain/grain size $(1.9 \mu \mathrm{m})$, and large number of boundaries exhibiting a misorientation greater than $15^{\circ}$ $\left(f_{\mathrm{HAB}}=54 \%\right)$. This indicates the occurrence of extended recovery (DRV), which occurs by the progressive accumulation of dislocations at low angle boundaries, leading to the increase of their misorientation and the formation of large angle grain boundaries [31]. In most common alloys, a clearly defined and relatively equiaxed crystallite structure is rapidly established with increasing strain. While the subgrain size is relatively insensitive to strain, the misorientations across subgrain walls increase with increasing deformation degree [32]. Furthermore, there is a general agreement to consider that the transformation of low angle boundaries into high angle boundaries is enhanced when the boundaries are pinned by small particles. At this temperature $\left(408^{\circ} \mathrm{C}\right)$ based in DSC results [13] still dissolving alloying elements and incipient fine precipitates are present, reducing the recovery capacity of the material, since they decrease its stacking fault energy and the dislocation mobility $[33,34]$. Therefore, the large deformation experimented by the Al 2024 tested at $408^{\circ} \mathrm{C}$ and $2.1 \mathrm{~s}^{-1}$ results in a dramatic increase in the high-angle boundary (HAB) area.

On the other hand, at lower test temperatures $\left(278-315^{\circ} \mathrm{C}\right)$ the stress-strain curves show considerable softening after reaching the peak stress. Part of this softening, especially at lower temperatures and higher strain rates, it is due to flow localization and void creation at strains close to those corresponding to steady state [28]. Additionally, the loss of solute by static precipitation during cooling to test temperature, and precipitate coarsening during torsion straining may also contribute to the sharp decrease in flow stress at lower test temperatures. On the other hand, the coarsening of particles facilitates additional DRV.

It is our contention that for samples tested at lower temperature than $360^{\circ} \mathrm{C}$ the influence of solid solution is decreased, and consequently the difference in microstructure between these experimental conditions is less pronounced (Fig. $4 \mathrm{~g}-\mathrm{j}$ ), showing elongated grains with low mean misorientation $\left(\bar{\theta}_{c}\right)$. Furthermore, the fracture ductility $\left(\varepsilon_{\mathrm{F}}\right)$ decreases notably as the strain rate rises and test temperature decreases. It is known that coarse precipitate formation in the period lasting between the solution treatment and the torsion testing, together with additional coarsening by deformation, significantly reduces the energy required to nucleate coarse voids in the grain interior, thus decreasing its intrinsic toughness [35]. The deformation under the lowest temperature $\left(278^{\circ} \mathrm{C}\right)$ and the highest strain rate $\left(4.5 \mathrm{~s}^{-1}\right)$ leads to work hardened microstructure as observed in Fig. $4 \mathrm{j}$ due to the presence of undeformed coarsen precipitates, producing large local strain gradients [36]. This work hardened microstructure with incipient formation of subgrains with misorientation higher than $2^{\circ}$ is responsible of the low mean misorientation $\left(\bar{\theta}_{c}\right)$ value $\left(7^{\circ}\right)$ observed for this torsion test condition.

On the opposite, it is worth noting that the $\mathrm{Al} 2024$ alloy tested at the highest test temperature $\left(467^{\circ} \mathrm{C}\right)$ at both strain rates showed limited ductility compared to that observed at lower temperatures (360 and $408^{\circ} \mathrm{C}$ ). This reduced ductility is due to high proportion of elements in solid solution. After a solution treatment at $467{ }^{\circ} \mathrm{C}$ for $15 \mathrm{~min}$ the $\mathrm{CuAl}_{2}$ and $(\mathrm{CuMg}) \mathrm{Al}_{2}$ precipitates have been completely dissolved, bringing copper and magnesium atoms into solid solution. Any dislocation moving through a solid solution will encounter friction drag thus raising the energy required for movement. Furthermore, the recovery processes are also hindered by a 
high solute atom concentration [37]. During the cooling to lower test temperatures $\left(\leq 408^{\circ} \mathrm{C}\right)$ and the subsequent deformation of the samples, it is likely that very fine particles start to precipitate statically (during the cooling stage), and dynamically (during torsion deformation), and contribute to the peak stress and also to the development of the different microstructures observed in the present study. At the highest test temperature, $467^{\circ} \mathrm{C}$, where the solute has a very strong effect on inhibiting recovery, less dynamic boundary rotation occurs and the initial structure of elongated rolled grains is thus retained (Fig. 4a and d).

On the other hand, the crystallographic texture evolution in the Al 2024 alloy (Fig. 5) under different torsion conditions is consistent with the simple shear texture reported for fcc metals deformed by crystallographic slip. It has been reported [32] that high-angle boundaries can be readily generated from low-angle random boundaries in the main torsion texture components $(A$, $\mathrm{B}$ and $\mathrm{C}$ ), by the nature of the crystallographic rotation field in simple shear, as it has been corroborated for the Al 2024 torsion tested at $408^{\circ} \mathrm{C}$ and $2.1 \mathrm{~s}^{-1}$ (Fig. 4b). For this test condition, the $\mathrm{C}$ component $\left\{\begin{array}{lll}0 & 0 & 1\end{array}\right\}<110>$ was found to be the strongest at the highest strain $\left(\varepsilon_{\mathrm{F}} \sim 8.2\right)$ (Fig. 5b). Additionally, at lower strains reached at the lowest test temperatures, the intensity of the B component $\left\{\begin{array}{lll}1 & 1 & 2\end{array}\right\}<1 \quad 10>$ was found to be stronger. These results are in agreement with previous works on torsion tests of aluminium alloys $[24,38-40]$, where the A component $\{111\}<110>$ was found to decrease rapidly with strain, being replaced by the $C\left\{\begin{array}{lll}0 & 0 & 1\end{array}\right\}<1 \quad 10>$ and the $B\left\{\begin{array}{lll}1 & 1 & 2\end{array}<<110>\right.$ components at large strains. The $C$ component was found to be weak at small strains, and to increase with strain up to about 5 , that is, the start of steady-state. Thus, for a strain of about 5 , the intensity of the $C$ component was seen to increase continuously to a value of 9-10 times random, while the intensity of the B orientation increased to a value of 3 times random. In the present investigation, at the torsion conditions where a steady-state was observed, for instance $408^{\circ} \mathrm{C}$ and $2.1 \mathrm{~s}^{-1}$, the $\mathrm{C}$ component was found to be the strongest. Furthermore, a faster decrease in the intensity of the $C$ component and increase of the $B$ component with increasing stress is expected [39]. This explains the higher intensity of the B component $\left\{\begin{array}{lll}1 & 1 & 2\end{array}\right\}<1 \quad 10>$ for the samples tested at lower test temperatures in the present study.

Finally, the room-temperature hardness of Al 2024 alloy torsion tested at different temperatures and two strain rates (2.1 and $4.5 \mathrm{~s}^{-1}$ ) was measured after quenching and after four months of natural ageing (Fig. 6). The microhardness of the torsion-deformed Al 2024 alloy reflects the microstructural evolution as a consequence of the torsion test, since during torsion deformation, grain refining, dynamic precipitation [12] and precipitate coalescence [41] are favoured. Additionally, as it has been mentioned previously, there is a monotonic decrease of solid solute concentration as testing temperature decreases. In this aluminium alloy, the precipitation hardening, which depends mostly on temperature, is the main responsible of the strengthening mechanisms to improve the strength. Thus, although torsion test is characterized by a shear strain gradient, which is cero in the torsion axis and maximum at the periphery of the torsion sample, microhardness gradients across the gauge diameter were not observed.

With respect to the as-received Al 2024 alloy having 138HV, the tested materials present a lower hardness. The highest average microhardness value of the torsion tested samples of $132 \mathrm{HV}$ (Fig. 6) has been achieved for the alloy deformed at $467^{\circ} \mathrm{C}$ and $4.5 \mathrm{~s}^{-1}$, after quenching and natural ageing of residuary solid solution. At $2.1 \mathrm{~s}^{-1}$, there is more time respect to the torsion test at $4.5 \mathrm{~s}^{-1}$, in addition to higher ductility, for precipitate coarsening before failure, decreasing the microhardness considerably at all test temperatures. On the other hand, at $4.5 \mathrm{~s}^{-1}$, there is enhanced dynamic precipitation due to higher dislocation density, but there is less time for precipitate coarsening due to lower $\varepsilon_{\mathrm{F}}$. Taking into account these facts, the decrease of microhardness with the low test temperatures is a consequence of the loss of solute available for fine scale hardening precipitation during the subsequent natural ageing. This loss of solute along torsion deformation, in turn, is due to static precipitation during the cooling to test temperature and to the deformation-induced precipitation [12]. Additionally, deformation assists in the coarsening of the already formed precipitates [41].

In summary, the microstructure and microhardness of the hotworked Al 2024 alloy depend on the temperature and strain rate of the torsion test, since these parameters determine the dynamic recovery degree and the refinement of the (sub)grain size and second phase precipitates.

\section{Conclusions}

Hot torsion tests to fracture were carried out on the aeronautical Al 2024 alloy, which was deformed by hot torsion after solution treatment and cooling to different test temperatures $\left(278-467^{\circ} \mathrm{C}\right)$, and two strain rates $\left(2.1\right.$ and $\left.4.5 \mathrm{~s}^{-1}\right)$. EBSD was employed to characterize the obtained microtexture and microstructure. The main conclusions of this study are as follows:

(1) The Al 2024 alloy torsion tested at the highest temperature $\left(467^{\circ} \mathrm{C}\right)$ and for both strain rates showed limited ductility compared to that tested at lower temperatures $\left(360-408^{\circ} \mathrm{C}\right)$. This is due to the high proportion of alloying elements in solid solution, which hinder dislocation movement and dynamic recovery (DRV) processes.

(2) At the lowest test temperatures, the flow softening observed in the stress-strain curves is sharper than at higher test temperatures mainly due to loss of solid solution and particle coarsening. Coarsened precipitates favour crack nucleation, thus decreasing the ductility.

(3) The highest ductility was observed at $408\left(\varepsilon_{\mathrm{F}} \sim 8\right)$ and $360^{\circ} \mathrm{C}$ $\left(\varepsilon_{\mathrm{F}} \sim 6\right)$, at the lowest strain rate $\left(2.1 \mathrm{~s}^{-1}\right)$. Alloying elements in solid solution, together with incipient fine precipitates formed during the cooling at these test temperatures slow down the recovery process, leading to a homogeneous and fine microstructure $(1.3-1.9 \mu \mathrm{m})$ by DRV. Thus, this is the most favourable temperature range for efficient hot workability.

(4) The Vickers microhardness at room temperature of the torsiondeformed Al 2024 alloy after natural ageing reflects the precipitate evolution during the torsion test, i.e. precipitation during cooling to test temperature, plus precipitate coarsening during the torsion test and finally, precipitation of the retained solid solution after processing.

\section{Acknowledgements}

Financial support from CICYT (Project MAT2009-14452) is gratefully acknowledged. C.M. Cepeda-Jiménez thanks the Spanish National Research Council (CSIC) for a I3P contract. We also thank F.F. González-Rodríguez for assistance during hot torsion. Finally, an especial mention in memory of P.J. González-Aparicio for his help and assistance with electron microscopy during all these years is made.

\section{References}

[1] M. Ueki, S. Horie, T. Nakamura, J. Mech. Work. Technol. 11 (1985) 365-376. [2] F.C. Liu, B.L. Xiao, K. Wang, Z.Y. Ma, Mater. Sci. Eng. A 527 (2010) 4191-4196. [3] P. Cavaliere, J. Light Metal 2 (2002) 247-252.

[4] H. Zhang, G.Y. Lin, D.S. Peng, J. Mater. Process. Technol. 148 (2004) 245-249.

[5] G.Y. Lin, Z.F. Zhang, D.S. Peng, J. Zhou, Acta Metall. Sin. 21 (2008) 109-115.

[6] H.J. McQueen, Metall. Mater. Trans. A 33 (2002) 345-362. 
[7] H.J. McQueen, in: T.G. Langdon, H.D. Merchant (Eds.), Hot Deformation of Aluminium Alloys, TMS-AIME, Warrendale, PA, 1991, pp. 105-120.

[8] M. Carsí, F. Peñalba, O.A. Ruano, O.D. Sherby, Metall. Mater. Trans. A 28 (1997) 1913-1920.

[9] S. Spigarelli, M. Cabibbo, E. Evangelista, J. Bidulská, J. Mater. Sci. 38 (2003) 81-88.

[10] A. Oudin, P.D. Hodgson, M.R. Barnett, Mater. Sci. Eng. A 486 (2008) 72-79.

[11] S. Spigarelli, M. El Mehtedi, P. Ricci, C. Mapelli, Mater. Sci. Eng. A 527 (2010) 4218-4228.

[12] C. Badini, F. Marino, E. Verné, Mater. Sci. Eng. A 191 (1995) 185-191.

[13] E. Hersent, J.H. Driver, D. Piot, Scripta Mater. 62 (2010) 455-457.

[14] D. Jorge-Badiola, A. Iza-Mendia, I. Gutierrez, J. Microsc. 228 (3) (2007) 373-383.

[15] C.M. Cepeda-Jiménez, M. Pozuelo, J.M. García-Infanta, O.A. Ruano, F. Carreño, Metall. Mater. Trans. A 40 (2009) 69-79.

[16] C.M. Cepeda-Jiménez, P. Hidalgo, M. Pozuelo, O.A. Ruano, F. Carreño, Mater. Sci. Eng. A 527 (2010) 2579-2587.

[17] D.S. Fields Jr., W.A. Backofen, Proc. Am. Soc. Test. Mater. 57 (1957) 1259.

[18] M. Carsí, R. Allende, F. Peñalba, J.A. Jiménez, O.A. Ruano, Steel Res. Int. 75 (2004) 26-32.

[19] C.E. Campbell, L.A. Bendersky, W.J. Boettinger, R. Ivester, Mater. Sci. Eng. A 430 (2006) 15-26.

[20] Y. Xue, H. El Kadiri, M.F. Horstemeyer, J.B. Jordon, H. Weiland, Acta Mater. 55 (2007) 1975-1984.

[21] J. Dennis, P.S. Bate, F.J. Humphreys, Acta Mater. 57 (2009) 4539-4547.

[22] Y. Huang, F.J. Humphreys, M. Ferry, Acta Mater. 48 (2000) 2543-2556.

[23] W. Blum, Q. Zhu, R. Merkel, H.J. McQueen, Mater. Sci. Eng. A 205 (1996) 23-30.
[24] T. Pettersen, E. Nes, Metall. Mater. Trans. A 34 (2003) 2727-2736.

[25] A. Gholinia, P. Bate, P.B. Prangnell, Acta Mater. 50 (2002) 2121-2136.

[26] G.R. Canova, U.F. Kocks, J.J. Jonas, Acta Metall. 32 (1984) 211-226.

[27] R.K. Islamgaliev, N.F. Yunusova, I.N. Sabirov, A.V. Sergueeva, R.Z. Valiev, Mater Sci. Eng. A 319-321 (2001) 877-881.

[28] B. Verlinden, P. Wouters, H.J. McQueen, E. Aernoudt, L. Delaey, S. Cauwenberg, Mater. Sci. Eng. A 123 (1990) 229-237.

[29] C.R. Brooks (Ed.), Heat Treatment, Structures and Properties of Nonferrous Alloys, American Society for Metals, Metals Park, OH, 1982, p.121.

[30] J.P. Lokker, A.J. Böttger, W.G. Sloof, F.D. Tichelaar, G.C.A.M. Janssen, S. Radelaar, Acta Mater. 49 (2001) 1339-1349.

[31] A. Dehghan-Manshadi, M.R. Barnett, P.D. Hodgson, Mater. Sci. Technol. 23 (2007) 1478-1484.

[32] M.R. Barnett, F. Montheillet, Acta Mater. 50 (2002) 2285-2296.

[33] S. Gourdet, F. Montheillet, Mater. Sci. Eng. A 283 (2000) 274-288.

[34] B. Eghbali, A. Abdollah-Zadeh, H. Beladi, P.D. Hodgson, Mater. Sci. Eng. A 435-436 (2006) 499-503.

[35] D. Dumont, A. Deschamps, Y. Brechet, Mater. Sci. Eng. A 356 (2003) 326-336.

[36] P.J. Apps, J.R. Bowen, P.B. Prangnell, Acta Mater. 51 (2003) 2811-2822.

[37] N. Jin, H. Zhang, Y. Han, W. Wu, J. Chen, Mater. Charact. 60 (2009) 530-536.

[38] F. Montheillet, M. Cohen, J.J. Jonas, Acta Metall. 32 (1984) 2077-2089.

[39] J.K. Solberg, H.J. McQueen, N. Ryum, E. Nes, Phil. Mag. A 60 (1989) 447-471

[40] H.J. McQueen, J.K. Solberg, N. Ryum, E. Nes, Phil. Mag. A 60 (1989) 473485.

[41] E. Cerri, E. Evangelista, A. Forcellese, H.J. McQueen, Mater. Sci. Eng. A 197 (1995) $181-198$. 